\title{
Developing Online Virtual Community by Facilitating Student Discussions
}

\author{
K. P. Hewagamage, Member, IEEE and IACSIT, K. M. G. B. Nishakumari, and G. N. Wikramanayake, \\ Member, IEEE and IACSIT
}

\begin{abstract}
In an online learning environment, it is a challenging task to motivate learners to participate in online discussions. Specially, if they are beginners in a programme and have less experience in using Internet and computers, students are more reluctant to interact with others. A Massive Online Course (MOC) usually has thousands of participants and it is very important to develop a learning community which interacts, collaborates and shares during the learning process in such courses. Discussion forums are the immediate method of communication available to develop this virtual community. However, having facilities in an environment is not enough to create the community. In this paper, we are presenting a case study based on the Virtual Learning Environment (VLE) of the Bachelor of Information Technology (BIT) which has a few thousands of registered students. The participation in the discussion forums of courses in the VLE is very poor irrespective of the number of students enrolled in each course. To study this situation, an analysis was carried out to find out causes for poor learner-learner interaction and some actions were taken to improve the situation in the VLE during the last few academic years. Structured discussions in a course, social interaction, recognition for participation and development of an FAQ page are some of those techniques. In this action research environment, we observed some positive developments as well as some actions that did not motivate student participation. We identified that the role of a facilitator is the most important factor according to the discussion statistics and qualitative analysis of messages during the last two academic years.
\end{abstract}

Index Terms-Virtual learning environment (VLE), discussion forums, facilitation, learner interaction, virtual community, motivation.

\section{INTRODUCTION}

Learning engagement is a very important matter that must be considered when conducting online courses based on the learner centric design. It cannot be done by forcing students to do things. Motivation is the invisible force that makes learners to perform better as well as to interact with one another in the learning environment. Teacher presence is a factor for learners' motivation to engage in learning activities and to develop the multidirectional communication [1]. "Online discussion forums" are facilities that integrate both learning engagement and teacher presence to develop the online learning community. However, it does not happen

Manuscript received October 14, 2011; revised October 29, 2011. This work was supported in part by the National e-Learning Centre Project funded by the Swedish International Development Agency (Sida)

Authors are with University of Colombo School of Computing (UCSC) (e-mail: kph@ucsc.lk,nkk@ucsc.lk, gnw@ucsc.lk). automatically, if there is no proper guidance and facilitation.

In this paper, we are reporting an action research work carried out to enhance the student participation in online discussion forums of the Virtual Learning Environment (VLE) (http://vle.bit.lk) in the Bachelor of Information Technology (BIT) degree programme. BIT [http://www.bit.lk] is conducted by the University of Colombo School of Computing (UCSC) to produce IT graduates to meet the national demand for IT Professionals. This programme has become very popular in Sri Lanka since its design for learning and evaluation is based on the open distance learning, as well as the affordability of cost of registration and examination compared to the average income of the general public. It is a three year degree programme where examinations are held at the end of each semester after 15 weeks of online course work. First year of the BIT programme, discussed in this paper, has 8 courses and there are approximately 3000 registered learners including repeaters. Hence, managing the BIT VLE, while facilitating a large learning community which consists of different types of learners with different set of skills, has become a challenging assignment during the last few years.

At the beginning of the BIT in the year 2000, UCSC offered it as an external degree where the university conducted only testing based on the published curriculum and teaching was carried out by third party institutes. Most of these institutes had never trained candidates for degree level programmes. After few years of its commencement, students' performance at the semester exams was decreasing gradually together with the popularity to attract new students (registration). A Learning Management System (LMS) was introduced as an alternative way to guide the learners using the supplementary Multiple Choice Question (MCQ) based online assignments [2]. This had some effects on reducing the failure rate and the dropout rate of the programme but the curriculum based testing was not enough to make a significant effect on the learners' performance, as we observed while conducting the programme. At the same time, the web-based LMS was an effective environment that can be used to motivate and facilitate self-learning in large study programmes.

In the next stage, the BIT LMS [3] was expanded with the learning resources and continuous integrated assessment activities to guide learners to follow the curriculum and to achieve the specified learning objectives. This integrated environment of learning and assessment is called the BIT Virtual Learning Environment (VLE) [http://vle.bit.lk]. There was a gap between learning resources and assessments that hindered learners' active engagement in learning. 
Learning activities are created to fill this gap and it gives an opportunity for learners to engage in learning. However, human mind always distract whenever it faces a problem which cannot be resolved by itself. Learners in such circumstances seek external help from fellow learners or facilitators in the course to follow their learning. Discussion forums are created in the VLE based on the learning structure in course syllabuses to facilitate the dialog among learners as a response to this requirement. However, we observed that learners do not engage as we expected in the discussion forums and there are several issues that must be addressed to develop effective learner centric discussions in a VLE. This paper presents the details of those issues together with the actions taken and the results of our initial evaluation.

Section II describes the literature of motivating students in online discussions. A brief overview of the learning structure and online forums are presented in Section III. We present, in Section IV, our observation of student participation in discussion forums. Section $\mathrm{V}$ is based on the quantitative and qualitative evaluation of the actions taken. Finally, we conclude the paper in Section VI.

\section{Literature OF Motivating OnLine STUDENT DISCUSSIONS}

Computer-mediated communication is considered as a primary mechanism to create and sustain learning communities in online courses by generating discussions and social presence [4]. However, the challenge is to design and facilitate such collaborative learning communities for different content domains and disciplines using the evolving tools and technologies made available for designers [5]. Even though Feenberg [8] indicated that the lack of face-to-face (f2f) and visual cues in online participation was a major barrier to online learning, Gunawardena and Zittle [4] argued that student perceptions of social presence was more important than the capacity of the medium used to capture gestures and intonations in online learning. Furthermore, online discussion was emphasized as the 'defining characteristic" of an online constructivist learning environment [6] that presents multiple perspectives to learners. Therefore, when designing a VLE and online discussion forums, topics of mutual interest among learners could be frequently used to build online learning communities [5].

Rovai [6] pointed out several advantages and disadvantages of using online discussion forums. The main strength lies in the ability to reflect on course content and other members' postings. Although several potential weaknesses also exist, such as overwhelming number of postings to read, small groups of students dominating the discussions, increased chance of misunderstandings and reduced student motivation to interact, he suggested that these weaknesses could be minimized using proper facilitation methods. In this paper, we are able to further strengthen this observation based on the case study presented.

In an adult learning context, motivation to learn was defined as the "tendency to find learning activities meaningful and to benefit from them" ([7], p4). Therefore, when considering adult students, motivation refers to the choices they make regarding activities and the amount of effort they put into learning those activities. Many factors can affect the motivation of students learning online such as difficulty with content, technology access problems, lack of communication skills, English as a second language and ignorance of students' needs [9]. Although technology access problems could be solved with proper technical assistance, language and communication barriers can be considered as critical factors that restrict active participation in online discussions. However, we identity in this study students who do not actively participate in discussions also benefit since they read others discussions irrespective of their language and communication skills.

\section{BIT VLE STRUCTURE AND ONLINE DISCUSSION FORUMS}

Although BIT is still not a fully online degree program, it has been transforming from a conventional external degree to an online degree using online education facilities during the last few years. The main change was based on the paradigm shift from the curriculum based testing to learner centric learning and assessment. VLE was the key instrument which facilitated this transformation. Modular Object-Oriented Dynamic Learning Environment (MOODLE) [http://www.moodle.org] which is the most popular open source LMS was used to set up the BIT VLE.

BIT degree program consists of 3 academic years which are divided into six semesters to conduct courses and relevant examination. There are 28 courses declared in the curriculum, some of which are compulsory for all registered students in the programme. A course is conducted from the beginning to the end in the given semester of the curriculum except the final year individual project. The syllabus of a course contains all required initial learning instructions for students, together with learning outcomes, instructional objectives, topics and sub-topics linked with relevant pages of reference books and assessment criteria. A course in the BIT VLE was developed based on this syllabus to facilitate students to navigate interactively, and to participate in learning and assessment activities while communicating with fellow learners and teachers/online facilitators. Hence, online discussion forums were created in a course for a structured dialog according to the subject matter content in the syllabus. Fig. 1 shows how forums are structured in a course.

If we use a single forum for all the discussions in a course, it could be a boring experience for learners since all learners are not interested in discussing every aspect in the syllabus. (This was identified in the evaluation as given in the section $\mathrm{V})$. Hence, the course page was designed to separate with respect to specific objectives and subject matter content as shown in the Fig. 1. Students were asked to follow this structure as a common policy in a course and a schedule for online discussions are declared at the beginning of the course. The students were informed about discussion forums and online assistance when they register to follow the program. (http://vle.bit.lk/mod/resource/view.php?id=2303) 


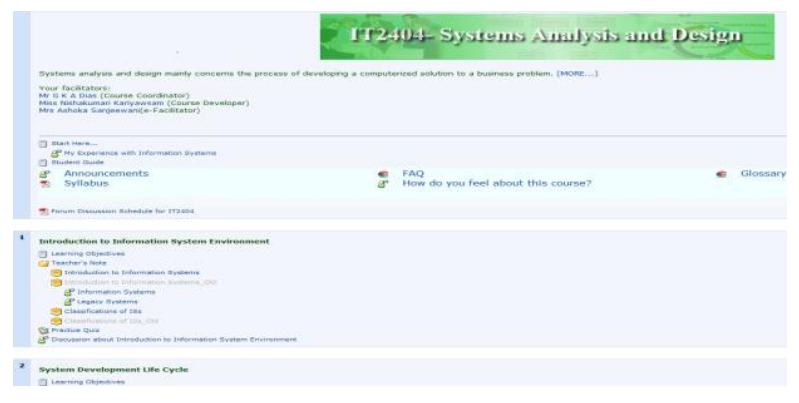

Fig. 1. Structured forum discussions in a course page

The general discussion policy used while designing the BIT VLE is summarized below.

- Each course has an announcement forum to communicate important notices which are posted by the e-facilitator to all students (No discussions).

- All students in a course are forced to subscribe to the announcement forum using the personal email address but they could select their subscription of all other forums depending on the interest.

- There is a forum called, "General Discussions" to discuss general matters related to the course.

- "How do you feel about this course?" is a forum for students to provide the feedback. At the end of a course, facilitator requests students to provide their feedback.

- A course has a social forum to develop mutual understanding and friendship among participants. Facilitators promote it at the beginning of the course.

- With respect to each section in the syllabus, a forum is created in the course page. Students are advised to discuss subject matters in the relevant forum.

- At the beginning of the course, the facilitator announces a forum discussion schedule to guide and to keep attention of students. Hence, there is an active forum for every week during the semester.

In order to motivate students to have a good subject matter based discussion, it is important to develop a user-friendly environment as an initial step towards building the virtual community. Hence, especially in the first semester online courses of the BIT programme, social forums were created inviting students to participate as the first forum discussion activity in the respective course. Different social activities were defined in each of the four courses in the first semester, namely "Edit Profile", "Virtual Canteen", "Mutual Interest" and "Internet Experience".

\section{StUdent PARTICIPATION IN ONLINE FORUMS}

There are over 2000 first year registered students in a course at any time during the semester. If $50 \%$ of these registered students post a single message during a week, we expect at least 1000 messages in a forum discussion. However, the actual number of messages posted in a course and the number of students who participated in the discussions (posting and replying messages) is very low compared to the total active students in a course (Details are given in TABLE I). Hence, the situation was monitored and a series of actions were taken to enhance the student participation.

Although there are more than 2000 students registered to follow first year courses in the BIT VLE, almost $50 \%$ of these students were facing problems to obtain Internet facility. Registration was increased during last two years but the rate of accessibility was not changed. Hence, this external factor has been negatively affecting the development of the virtual community during last few years.

When the VLE was designed, we emphasized that the role of a facilitator is a very important factor as it would affect the student participation in discussion forums and the development of the virtual community. Hence, a guideline was prepared to formalize facilitators' interaction with students and they were instructed to monitor the forums at a regular interval, preferably on a daily basis in addition to subscribing them using email. When a student posts a message expecting assistance/opinion, facilitator is supposed to participate in the discussion by inviting others to provide their feedback. If a question is answered directly, there won't be any opportunity to construct the knowledge with respect to social constructivism. The facilitator is not the teacher (Subject Matter Expert - SME) of the course, who prepares the final assessment in the course. But the facilitator was asked to communicate regularly with the SME to obtain their feedback to enhance the discussion. However, students were not happy since they couldn't communicate directly with the SME who only observed the discussions, to find out whether these discussions were related to the assessment of the course.

A facilitator is not an individual tutor to help all these students in the programme. Since the number of students in a course is usually greater than or equal to 500 in a typical BIT online course (this number is more than 2000 in first year courses), we could not try out some of the traditional facilitation techniques to motivate students for constructive discussions. However, many students were repeatedly asking routine administrative questions in many of these discussion forums. It was not possible to neglect their messages when we were trying to motivate students to participate in constructive dialogs but such messages were creating unwanted disturbances. It was worst when the same question was asked by different students at different times in the same discussion. This situation led us to develop a Frequently Asked Questions (FAQ) page as a resource to improve the qualitative discussions in forums, by directing/guiding them to use the FAQ to find answers before posting administrative questions. FAQ which could be accessed publicly (http://vle.bit.lk/file.php/1/FAQ/new/index.html), is updated at the end of each semester by facilitators based on the discussions took place in the courses. At the same time, students were strictly instructed at the beginning of the course to verify their question or comment with respect to previous discussions in the forums of course using the search facility.

In managing these FAQs, we identified the requirement of setting up a Subject Matter based FAQ in the courses since the general FAQ deals mainly with administrative matters. At the same time, it could be a reflection of last years' discussion forums, which are not visible to the current students. The participation of SME is very important for the development of a course FAQ and it could become a learning resource that reflects previous interactions of the learners in the course. 
Generally, the students' behaviour is acceptable to develop the collaborative learning environment in the BIT VLE but we occasionally encounter students who do not follow the instructions given and general ethics in the online communication. For example, some students started criticizing other students openly in forums due to personal issues and some of them were abusing others (specially female students) by sending inappropriate messages when they do not respond to messages or requests. The coordinator had to give warnings in such situations both openly and privately. In addition, a netiquette for all online courses were established to minimize misunderstandings among students, especially in discussion forums. This "Netiquette for all BIT courses" were published openly allowing anyone to access from outside of the BIT VLE (http://vle.bit.lk/mod/resource/view.php?id=3954). These guidelines helped to enhance the qualitative value of online discussions while motivating all students irrespective of their ethnic values and social status.

When the BIT VLE was set up for online learning, we observed the main issue for the poor participation was due to lack of recognition for their contribution. In a way, this was an attitude issue of students, some of which were selfish when sharing what they knew. We did not want to give some free marks to motivate these students and to change this attitude of learners. But we established an informal recognition for good contributors. Details are given in the next sub-section.

\section{A. Informal Recognition - "An Award for the Best e-Learner of the Semester"}

Active participation could be measured by the number of good questions posted for discussions based on the learning activities or providing feedback for others messages. Providing marks for messages and replies in a massive learning environment is not practical without considering qualitative aspects of each message. Hence, we introduced a kind of informal recognition, called "Best e-Learner of the Semester" to promote students participation in discussion forums. Since the best e-learners are not only those who discuss things in the forums, we linked this award with their performance in assessments to select more suitable candidates for the award.

To select the best e-Learners with respect to each semester of the programme, following criteria is used;

1) Identify the forum participation ranking $\left(W_{j}\right)$ for each course using following conditions:

$a v g=($ Total postings in the given course / Total

number of users in the forum discussions)

$$
\begin{aligned}
& W_{j}(\geq a v g)=1, \quad W_{j}(j \geq 200 \% \times a v g)=1.2, \\
& W_{j}(j \geq 80 \% \times a v g)=0.8, \quad W_{j}(j \geq 60 \% \times a v g)=0.6, \\
& W_{j}(j \geq 40 \% \times a v g)=0.4, \quad W_{j}(\geq 20 \% \times a v g)=0.2,
\end{aligned}
$$

2) Calculate the forum score (FS) for each student using their online formative assignments marks

$$
F S=\text { Assignments } \operatorname{avg} \text { (for the given student) } \times W_{j}
$$

3) Calculate the average forum score $\left(F S_{\text {avg }}\right)$ for all compulsory courses in the given semester.

4) Select the best $10 \%$ based on the $F \mathrm{~S}_{\text {avg }}$

5) Choose the best student from qualitative analysis of forum postings.

By giving a special award for students at the annual diploma award ceremony, the recognition was given for students' participation in the forum discussions to enhance the effectiveness of the BIT VLE. Four awards were given for the semester 1 to 4 of the study programme. (http://dev.lms.bit.lk/vle/mod/forum/discuss.php?d=4604).

\section{Evaluation}

BIT VLE was set up according to the description given in the previous sections and the student participation in discussion forums was monitored to identify the effectiveness of the strategies adopted. TABLE I gives the basic statistics of discussion forums in the Semester 1 courses during 2010 and 2011. IT1104, IT1204, IT1304 and IT1404 are compulsory courses in this semester. In addition, an

\begin{tabular}{|c|c|c|c|c|c|c|c|c|}
\hline Course Code (Semester 1) & \multicolumn{2}{|c|}{ IT1104 } & \multicolumn{2}{|c|}{ IT1204 } & \multicolumn{2}{|c|}{ IT1304 } & \multicolumn{2}{|c|}{ IT1404 } \\
\hline Academic Year & 2010 & 2011 & 2010 & 2011 & 2010 & 2011 & 2010 & 2011 \\
\hline Active students & 2321 & 3173 & 2204 & 2948 & 2098 & 2805 & 2160 & 2942 \\
\hline Forum participation (Messages) & 1283 & 1012 & 1009 & 888 & 1011 & 508 & 1094 & 1316 \\
\hline Forum readings (Messages) & 27390 & 37744 & 16757 & 19983 & 13716 & 12113 & 17605 & 34033 \\
\hline Avg. participation per student & 0.6 & 0.3 & 0.5 & 0.3 & 0.5 & 0.2 & 0.5 & 0.4 \\
\hline Avg. reading per student & 11.8 & 11.9 & 7.6 & 6.8 & 6.5 & 4.3 & 8.2 & 11.6 \\
\hline
\end{tabular}
online survey was set up to gather students' feedback on discussion forums (http://kwiksurveys.com?u=bit2011).

TABLE I: STUDENT PARTICIPATION IN SEMESTER 1 DISCUSSION FORUMS

According to the statistics in the TABLE I, the student participation and reading in online discussion forums have decreased irrespective of our effort to develop active virtual learning community in the BIT VLE. During 2010, all four courses were facilitated by a single facilitator but the job was distributed among four part time facilitators during the semester 1 of year 2011 (the semester ended in March 2011). All facilitators received almost equal level of training before they started the facilitation. When we investigated messages of these discussion forums qualitatively, we were able to identify the importance of the human factor in communicating and interacting in online forums. Students participation was directly linked how the facilitator reacted and connected with other learners in the online forums. Hence, it gave the evidence to justify that the facilitation is artistic than technical in online discussion forums to promote 
students.

Social forum was a good initiative to develop the mutual understanding and friendship among participants in online discussion. However, having similar social forums in parallel did not bring the desired results. Every forum has a limited time span and these forums were not active throughout the course. For example, messages posted in the social forums at the very beginning of the course, got a good attention and there was a discussion. On the other hand, messages posted after first 4 weeks of introducing the social forum was not getting enough attention. Rather than posting a new message, discussing under one thread seemed to be more popular among students since others were willing to participate. We also noticed that when a female student started a thread, it was getting attention from others. Hence, having different social forums at different times during the semester may motivate the learners as well as enhance their soft skills, especially with respect to communicating with others during the course. At the same time, poor participation of the facilitator in some social forums affected badly to keep the discussions active.

Other than facilitators, the number of experienced learners in a course affects the constructive discussions in a forum. Hence, inviting volunteers who may be senior/past students or individuals in the relevant industry would be an alternative strategy. However, BIT VLE is a closed environment with respect to regulation for monitoring and evaluation and it does not allow outside volunteers to take part in any formal academic activities without prior permission from the relevant authority. Technically, this problem could be solved by linking Moodle discussion forums with a Google discussion forum which could be an open discussion with anyone. This allows students to interact with a large open community.

Local culture and social recognition are also key forces that determine individual interaction in an online environment. Unfortunately, many novice students in higher education believe that asking a question is offensive against their teachers based on their experience in school education. At the same time, asking a wrong or meaningless question may be considered as an act of inability of an individual. We observed that this situation also has affected some personal behavior. The recognition such as the best e-learner award of the semester has changed these attitudes of online learners to some extent.

\section{A. Students' Feedback for Evaluation}

After the last semester, an online anonymous survey was carried out to gather the students' feedback on online discussion forums. It was published at http://kwiksurveys.com?u=bit2011. More than 80 students participated in this online survey to provide the feedback.

More than $80 \%$ of students believe that discussion forums benefit for their learning. However, majority of them (45\%) are readers only. No one said that forums were useless learning resources but there is a minority group (13\%) who believes that forums did not help them. Fig 2 illustrates their responses.

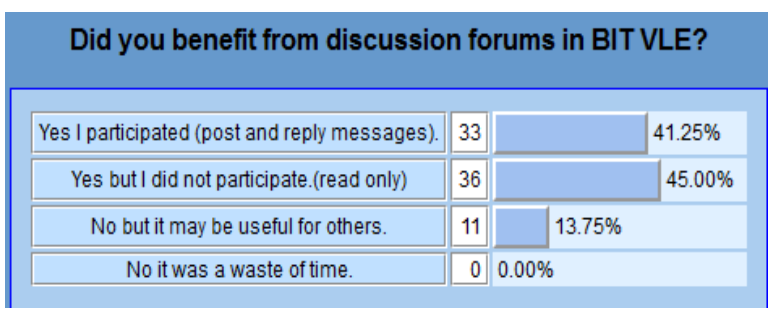

Fig. 2. Learners' view of discussion forums

The discussion forums were structured based on the sections in the syllabus. This had helped some students (30\%) for their participation (Fig. 3) but the majority of students were not following forum discussion schedules according to the survey. Later, it was revealed that many students were not properly informed about it.

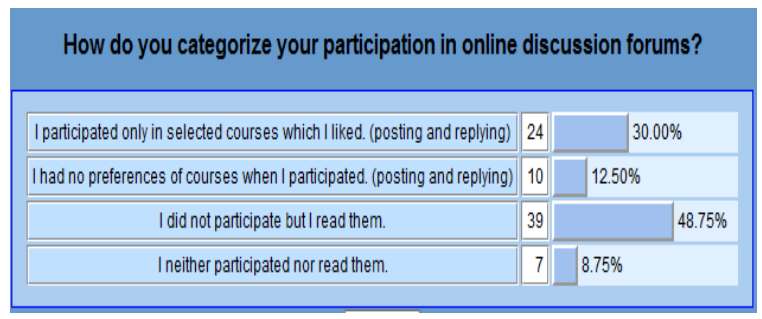

Fig. 3. Types of Participation In Discussion Forums

All students were very much like social forums introduced to develop informal friendship and interaction among the community. However, the majority was not participating in them as shown in the Fig. 4.

\begin{tabular}{|c||c||c|c|}
\hline Yes I participated them (posting and replying) & 26 & & \\
\hline Yes but I didn't participate them & 34 & & \\
\hline No but it might be helpful for others & 14 & & \\
\hline No it didn't make any benefit & 2 & $24.21 \%$ \\
\hline
\end{tabular}

Fig. 4. Students' preference about social forums

"Best e-Learner Award of the Semester" which was introduced to recognize participation in forum discussions had motivated students but there were some students who did not know about such recognition as shown in Fig. 5. This again indicated poor awareness about the available facilities and opportunities among students in the VLE.

\begin{tabular}{|c||c||c|c|}
\hline \multicolumn{2}{|c||}{ Yes I like it. } & 46 & \\
\hline Yes but I do not like such awards. & 10 & & $12.82 \%$ \\
\hline No I like to know about it. & 18 & $23.97 \%$ \\
\hline No I do not like such awards/recognition. & 4 & $5.13 \%$ \\
\hline
\end{tabular}

Fig. 5. Students' preference of best e-learner award

\section{CONCLUSION}

In this paper, we presented our experience in motivating students to participate in online discussions as a strategy to develop the virtual learning community in the BIT VLE. In a massive online learning environment, it is a hard challenge to motivate students to participate in constructive discussion when there are learners with different styles of interaction as shown in the survey. Having identified the context of the 
learning environment, we carried out several activities as described in this paper to develop the BIT virtual learning community. This paper reports those activities and our evaluation of online discussion forums.

Online courses were designed to have structured discussions during all weeks of the semester. These discussions were supposed to fill the gap between learning resources and learning activities, when students face problems of understanding or interpreting what they learn. We also introduced social forums as non-academic forums to develop mutual understanding and friendship among participants. However, facilitators are the main role players in these discussions to guide and motivate learners to share their learning experience. In our evaluation, we observed some evidence based on last two years of forum interaction to justify this role of a facilitator which depends on the personal capacity to communicate with the others. Feedback gathered after the last semester also indicates the importance of facilitation to develop the online virtual community. Comparing with other learning context, we also noticed social and local culture have some effect on learner participation in online discussions based on their feedback.

Actions/activities which we carried out as presented in this paper, were affected for the positive development in the BIT VLE. However, we believe that there are more things that could be done to promote student participation in online forums to develop the virtual learning community.

\section{REFERENCES}

[1] C. Baker, "The Impact of Instructor Immediacy and Presence for Online Student Affective Learning, Cognition, and Motivation". The Journal of Educators Online. Vol. 7, No. 1, 2010.

[2] K. P. Hewagamage, V. K. Samaranayake, A. R. Weerasinghe, and G. I. Gamage, "Facing Challenges of an External Degree Program using ICT: A Case study of University of Colombo School of Computing". Proceedings of Digital Learning 2005 (DL2005), New Delhi, India, October 2005.

[3] K. P. Hewagamage, K.H.R.A Peiris, W.A.U.C. Weerakoon, "Evaluation and Adaptation of Learning Management System (LMS) for Higher Education", Proceedings of Digital Learning 2006 (DL2006), Bangkok, Thailand, May 2006.

[4] C. N. Gunawardena, and F. J. Zittle, "Social Presence as a Predictor of Satisfaction within a Computer-mediated Conferencing Environment". American Journal of Distance Education. Vol. 11, No. 3, pp. 8 -26, 1997.

[5] C. Gunawardena, L. Ortegano-Layne, K.. Carabajal, K. Frechette, K. Lindemann, and B. Jennings, "New Model, New Strategies: Instructional design for building online wisdom communities". Distance Education, Vol. 27, No. 2, pp. 217-232, 2006.

[6] A. P. Rovai, "Facilitating online discussions effectively". The Internet and Higher Education., Vol. 10, No. 1, pp. 77-88, 2007.

[7] R. J. Wlodkowski, "Enhancing Adult Motivation to Learn: a Comprehensive Guide for Teaching All Adults". San Francisco, John Wiley and Sons, 1999.
[8] A. Feenberg, "The Written World: On the Theory and Practice of Computer Conferencing". In Mindweave: Communication, Computers and Distance Education. R. Mason and A. Kaye (Eds.). Oxford, Pergamon Press, pp. 22-39, 1989

[9] P. A. Beffa-Negrini, N. L. Cohen, and B. Miller, "Strategies to Motivate Students in Online Learning Environments". Journal of Nutrition Education and Behavior, Vol. 34, No. 6, pp. 334-340, 2002.

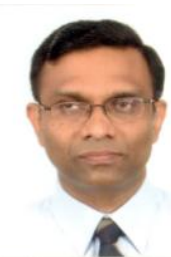

Dr. K. P. Hewagamage obtained his B.Sc. special degree in Computer Science (First Class Honors) from the University of Colombo and the Doctor of Information Engineering from Hiroshima University in Japan. Professor Mohan Munasinghe Award for the outstanding computer science graduate in 1994, the best paper award at IEEE International Conference of Visual Languages in 1999, an award for the excellence in research by the University of Colombo in 2004 and 2006, are some of awards received for his academic activities.He has more than 80 publications in International peer reviewed Journals and Conference Proceedings. He is a senior member of IEEE, an academic advocate of ISACA and a member of ACM. He was a chair of IEEE Computer Society Chapter in Sri Lanka. Dr. K. $\mathrm{P}$. Hewagamage is a senior lecturer in computer science at the University of Colombo School of Computing (UCSC) and the coordinator of National e-Learning Centre Project funded by Swedish International Development Agency. He is a visiting researcher at the Department of Computer and System Science, Stockholm University until end of 2011.

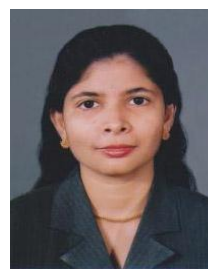

Mrs. K. M. G. B. Nishakumari obtained her B.Sc. degree in Physical Science (First class) from the University of Colombo, Sri Lanka in 2003 and BIT (Bachelor of Information Technology) degree (second lower class) from the University of Colombo, Sri Lanka in 2005. Recently, she obtained her M.Sc. degree in e-Learning from the University of Edinburgh, UK in 2010.

Her major field of study is e-Learning and Instructional Design. She has more than 8 years experience working in this field preparing and conducting online courses at UCSC.

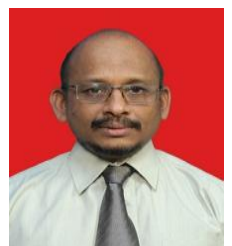

Prof. G. N. Wikramanayake obtained his B.Sc. degree in Statistics and Mathematics (First Class Honours) from the University of Colombo in 1984 He obtained his M.Sc. in Computer Science from Cardiff University, UK in 1989 and $\mathrm{PhD}$ in Computer Science from Cardiff University, UK in 1996. His $\mathrm{PhD}$ research was in the database field.

$\mathrm{He}$ is a professor and director of the University of Colombo School of Computing (UCSC), Sri Lanka and has served the university for over 25 years. He has served as a visiting researcher at Umea University, Stockholm University and University of New Mexico during 2008-2009. He has more than 60 publications in International peer reviewed Journals and Conference Proceedings. His interests are in statistics, database technology and e-learning.

Prof. Wikramanayake was awarded the most outstanding computer science graduate in 1984 and the University of Colombo research award in 2005. He is a senior member of IEEE and a council member of BCS, UK. He is the chair of BCS Sri Lanka Section and has held executive posts in IEEE Sri Lanka Section and the Computer Society of Sri Lanka. He has chaired conference organizing committees and is an associated editor of an international journal. 